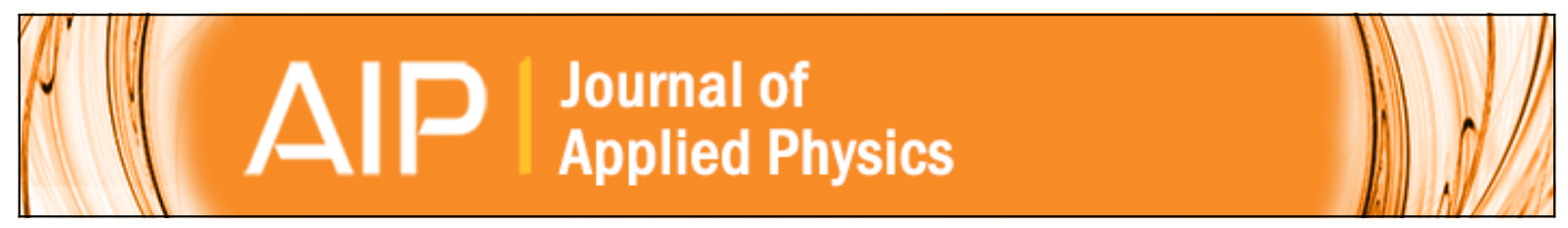

\title{
Fundamental mechanisms of focused ion beam guided anodization
}

Zhipeng Tian, Kathy Lu, and Bo Chen

Citation: Journal of Applied Physics 108, 094306 (2010); doi: 10.1063/1.3500513

View online: http://dx.doi.org/10.1063/1.3500513

View Table of Contents: http://scitation.aip.org/content/aip/journal/jap/108/9?ver=pdfcov

Published by the AIP Publishing

\section{Articles you may be interested in}

MgB 2 grain boundary nanobridges prepared by focused ion beam

J. Appl. Phys. 105, 013924 (2009); 10.1063/1.3063688

Gas-assisted focused electron beam and ion beam processing and fabrication

J. Vac. Sci. Technol. B 26, 1197 (2008); 10.1116/1.2955728

Rapid nanopatterning of a Zr-based metallic glass surface utilizing focused ion beam induced selective etching Appl. Phys. Lett. 89, 143115 (2006); 10.1063/1.2360181

Ideally ordered $10 \mathrm{~nm}$ channel arrays grown by anodization of focused-ion-beam patterned aluminum J. Vac. Sci. Technol. B 23, 559 (2005); 10.1116/1.1884123

High-speed focused-ion-beam patterning for guiding the growth of anodic alumina nanochannel arrays Appl. Phys. Lett. 82, 1281 (2003); 10.1063/1.1555689

\section{MIT LINCOLN} LABORATORY CAREERS

Discover the satisfaction of innovation and service to the nation
- Space Control

- Air \& Missile Defense

- Communications Systems \& Cyber Security

- Intelligence, Surveillance and

Reconnaissance Systems
- Advanced Electronics

- Tactical Systems

- Homeland

Protection

- Air Traffic Control

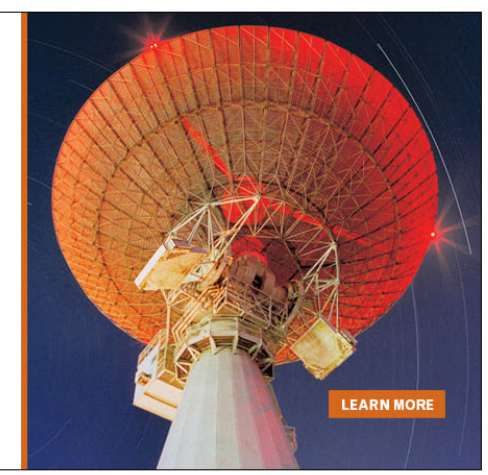




\title{
Fundamental mechanisms of focused ion beam guided anodization
}

\author{
Zhipeng Tian, Kathy Lu, ${ }^{\text {a) }}$ and Bo Chen \\ Department of Materials Science and Engineering, Virginia Polytechnic Institute and State University, \\ Blacksburg, Virginia 24061, USA
}

(Received 19 July 2010; accepted 9 September 2010; published online 2 November 2010)

\begin{abstract}
This paper is focused on understanding the fundamental mechanisms of focused ion beam guided anodization and the unique capabilities of generating new patterns based on such an understanding. By designing proper interpore distance, pore arrangement, and pore shape during focused ion beam patterning, nonspherical pore shape and nonhexagonal patterns can be obtained by further anodization. The electrical field and the mechanical stress field around each focused ion beam patterned concave dictate the pore formation and growth. The oxide barrier layer thickness and shape around the focused ion beam guided pores affect new pore formation and the meshing of different size pores. (C) 2010 American Institute of Physics. [doi:10.1063/1.3500513]
\end{abstract}

\section{INTRODUCTION}

Conventional anodization can only produce monosized, spherical-shaped, and hexagonally arranged pore patterns regardless of electrolytes or anodization conditions. The anodization process and pore pattern periodicity are sensitive to applied voltage, current density, temperature, and $p \mathrm{H}$ value of the electrolyte. ${ }^{1-4}$ Efforts have been devoted to creating regular pore arrays through guiding patterns formed before the anodization. One example is creating shallow strips, spots, or both kinds of features on the metal surface before the anodization from different electropolishing conditions. ${ }^{5}$ These shallow surface features are generally on the scale of several nanometers. However, they are not effective in guiding the anodization and the relationship between the electropolished features and the anodized patterns is unclear. Other patterning methods include nanoindentation ${ }^{7}$ and nanoimprint using $\mathrm{SiC}$ or $\mathrm{Si}_{3} \mathrm{~N}_{4}$ molds. ${ }^{8-12}$ However, these methods have inherent disadvantages in guiding pore pattern formation. Both nanoindentation and nanoimprint are contact methods. For the nanoindentation, the probe tip greatly influences pore shape and depth. Load variation and tip wear/ deformation create different pore sizes/shapes. Often times, only triangular or diamond pores can be produced. For the nanoimprint method, any misalignment between the mold and the substrate can cause local pressure variation and thus inhomogeneous pores or even defects.

To avoid the undesirable characteristics and overcome the intrinsic limitation of the contact mode patterning, holographic lithography ${ }^{13}$ and focused ion beam (FIB) lithography ${ }^{14-16}$ have been used to create patterns on the $\mathrm{Al}$ surface. The holographic lithography can pattern large areas but is restricted by the light wavelength and the grating precision. The pore size and the interpore distance are difficult to control. In contrast, the FIB lithography has a much better resolution and can create a variety of pore patterns without any mask. The ion beam spot size can be adjusted to less than $10 \mathrm{~nm}$ and the patterning process is relatively fast. ${ }^{17-19}$ However, the FIB pattern guided anodization is not well un-

${ }^{a)}$ Electronic mail: klu@vt.edu. derstood and its potential in creating complex pore patterns needs to be explored. There is no agreement about the specific function of the patterned features in guiding further pore growth during the anodization. Some studies indicate that the patterned concave features should be deeper than $5 \mathrm{~nm}$. $6,14,15$ However, the correlation between the guiding patterns and the anodized patterns are not established. In addition, the vast majority of the anodization studies are focused on hexagonal pore patterns. The pore sizes are the same and the pore shapes are spherical. Recently, some studies reported that square pore shapes can be created by the SiC mold indentation of the $\mathrm{Al}$ surface. ${ }^{7,20,21}$ But the anodization time is short with a large current density, which can only explain the formation of individually patterned pores at the unsteady state.

This study is focused on understanding the guiding function of the FIB patterned concaves during the Al anodization. The effects of the electrical field and the mechanical stress field around the patterned concaves on the subsequent pore formation and growth during the anodization are analyzed. Based on the theoretical understanding, multiple-sized pore arrays, different pore shapes, and unique pore arrangements are created. The knowledge gained should be applicable to other metal anodization systems with proper adjustment.

\section{THEORETICAL DISCUSSION}

During the anodization, the pore development in the guided pore growth mode is different from that in the selforganized pore growth mode because pore nucleation sites in the former case are predefined. With the existence of predesigned pores, further pore development during the anodization proceeds under the influence of two fields: electrical field and mechanical stress field. However, the significance of these two fields varies.

\section{A. Electrical field}

During the anodization, $\mathrm{Al}^{3+}$ ions are mobile in the oxidized $\mathrm{AlO}_{\mathrm{x}}(0<\mathrm{x}<1.5)$ layer around the pores and migrate from $\mathrm{Al}$ across the $\mathrm{Al} / \mathrm{AlO}_{\mathrm{x}}$ interface into the oxide barrier layer in the presence of the voltage. The $\mathrm{Al}^{3+}$ ions near the 
oxide/electrolyte interface drift through the $\mathrm{AlO}_{\mathrm{x}}$ layer and eject into the solution at the oxide/electrolyte interface. $\mathrm{O}^{2-}$ ions originate from water at the oxide/electrolyte interface and migrate into the barrier layer. More $\mathrm{AlO}_{\mathrm{x}}$ forms in the barrier layer. ${ }^{22}$ The $\mathrm{AlO}_{\mathrm{x}}$ outer layer, sometimes aluminum hydroxide, at the oxide/electrolyte interface dissolves to maintain charge neutrality. $\mathrm{Al}^{3+}$ ion loss to the electrolyte is a prerequisite for the $\mathrm{AlO}_{\mathrm{x}}$ barrier layer growth. For the pore growth front, there are four layers to be considered from the electrolyte to the Al metal: the Gouy-Chapman layer in the electrolyte near the oxide/electrolyte interface, the Helmholtz layer at the oxide/electrolyte interface, the growing oxide barrier layer, and the metal layer extending far into the $\mathrm{Al}^{23}$ Faster ejection of $\mathrm{Al}^{3+}$ ions into the electrolyte and $\mathrm{O}^{2-}$ migration to the metal/oxide interface facilitate pore surface oxidation and pore growth. The oxide layer is generally $\mathrm{O}^{2-}$ deficient because of the slow $\mathrm{O}^{2-}$ diffusion.

Based on the field-enhanced oxide dissolution theory, ${ }^{24-28}$ the pore bottom ion dissolution and diffusion are the main events during the steady state anodization. As a result, preferential dissolution of $\mathrm{AlO}_{\mathrm{x}}$ and pore growth mainly occur at the pore bottom. The voltage across the four layers from the electrolyte to the metal can be expressed as

$$
\mathrm{V}_{\mathrm{E}}=\mathrm{V}_{\mathrm{G}}+\mathrm{V}_{\mathrm{H}}+\mathrm{V}_{\mathrm{O}}+\mathrm{V}_{\mathrm{M}}
$$

where $\mathrm{V}_{\mathrm{G}}, \mathrm{V}_{\mathrm{H}}, \mathrm{V}_{\mathrm{O}}$, and $\mathrm{V}_{\mathrm{M}}$ are the respective voltages across the Gouy-Chapman layer, the Helmholtz layer, the growing oxide layer, and the metal layer. $\mathrm{V}_{\mathrm{H}}$ and $\mathrm{V}_{\mathrm{M}}$ are related to the $p \mathrm{H}$ of the electrolyte and the metal resistivity and do not change significantly with the anodization. $\mathrm{V}_{\mathrm{H}}$ can be expressed as ${ }^{29}$

$$
\mathrm{V}_{\mathrm{H}} \approx-\frac{\alpha k T}{e}(p H) .
$$

In Eq. (2), $k$ is Boltzmann constant, $T$ is temperature, $e$ represents the unit charge of a single electron, and $\alpha$ is a constant. $\mathrm{V}_{\mathrm{O}}$, however, increases significantly with the anodization time due to the oxide layer thickness increase. Since $V$ is mostly constant, $\mathrm{V}_{\mathrm{G}}$ is sufficiently high at the beginning of the anodization. This ensures intense transport of the electrolyte ions to the oxide layer across the Gouy-Chapman layer. As $V_{O}$ increases, $V_{G}$ decreases and the ion transfer slows down. The formation of the oxide layer also slows down. If the pores are assumed to have a hemispherical shape, the electrical field around the pores generated by charge $Q$ can be approximately described as ${ }^{12}$

$$
E=\frac{1}{2 \pi \varepsilon} \frac{Q}{L},
$$

where $E$ is the electrical field at the point of interest, $L$ is the distance between the charge center and the examined point, and $\varepsilon$ is the effective permittivity of the material

$$
\varepsilon=\frac{\left(R_{2} \varepsilon_{1}-R_{1} \varepsilon_{2}\right) \ln \frac{R_{2}}{R_{1}}}{\left(R_{2}-R_{1}\right) \ln \frac{R_{2} \varepsilon_{1}}{R_{1} \varepsilon_{2}}} .
$$

$\varepsilon_{1}$ and $\varepsilon_{2}$ are the dielectric permittivity of $\mathrm{Al}_{2} \mathrm{O}_{3}$ and $\mathrm{Al}$, respectively. $R_{1}$ is the pore diameter and $R_{2}$ is the distance from the pore center to the oxide barrier layer outer boundary. The derivation of Eq. (4) is given in the Appendix. As Eq. (3) shows, the electrical field diminishes from the pore center to the barrier layer outer boundary. The pore growth in the direction perpendicular to the pore walls completely stops when the oxide layer is thick enough to reach $\mathrm{V}_{\mathrm{G}}=0$.

When the FIB patterned concaves are present, ion diffusion across the flat $\mathrm{Al}$ surface is much slower because the $\mathrm{Al}$ on the flat surface has much fewer defects and no foreign ion implantation compared to the surrounding areas of the concaves patterned by the FIB. As the anodization continues, the pore growth rate in the pore diametrical direction decreases and reaches zero when the oxide layer is thick enough to reach $\mathrm{V}_{\mathrm{G}}=0$. The applied voltage controls the largest thickness of the barrier layer. At the pore bottom, the curvature is larger than that at the pore walls. Based on the fieldenhanced oxide dissolution theory, ${ }^{24-28}$ the pore bottom ion dissolution and diffusion are the main events during the steady state anodization; the continuous loss of $\mathrm{Al}$ at the metal/alumina interface and the dissolution of $\mathrm{Al}_{2} \mathrm{O}_{3}$ at the alumina/electrolyte interface reach a balance, generating a steady state anodization so that the pores grow deeper with time.

\section{B. Mechanical stress field}

During the anodization, the Al material undergoes a series of changes under the electrical field, including the oxidization of the $\mathrm{Al}$ matrix to $\mathrm{AlO}_{\mathrm{x}}$. The mechanical stress field mainly comes from the volume expansion of $\mathrm{Al}$ to $\mathrm{AlO}_{\mathrm{x}}$ due to the oxidation of the $\mathrm{Al}$ metal. The molar volume expansion can be expressed as

$$
\mathrm{V}_{\mathrm{m}}=\frac{\mathrm{M}_{\mathrm{AlO}_{\mathrm{x}}}}{\rho_{\mathrm{AlO}_{\mathrm{x}}}}-\frac{\mathrm{M}_{\mathrm{Al}}}{\rho_{\mathrm{Al}}} .
$$

$\mathrm{V}_{\mathrm{m}}$ is the molar volume expansion of $\mathrm{Al}$ to $\mathrm{AlO}_{\mathrm{x}} \cdot \mathrm{M}_{\mathrm{AlOx}}$ and $\mathrm{M}_{\mathrm{Al}}$ are the molecular weights of $\mathrm{AlO}_{\mathrm{x}}$ and $\mathrm{Al}$, respectively. $\rho_{\mathrm{AlOx}}$ and $\rho_{\mathrm{Al}}$ are the densities of $\mathrm{AlO}_{\mathrm{x}}$ and $\mathrm{Al}$, respectively. $\mathrm{V}_{\mathrm{m}}$ equals to about $2.75 \mathrm{~cm}^{3} / \mathrm{mol}$ when $\mathrm{x}$ is 1.5 . For a specific anodization condition, the total amount of $\mathrm{Al}$ anodized can be estimated by measuring the $\mathrm{Al}^{3+}$ concentration in the electrolyte, $\mathrm{Al}_{\mathrm{aq}}^{3+}$, and relating this value to the total amount of oxidized $\mathrm{Al}$ calculated from the charge flow during the anodization $\left(\mathrm{Al}_{\mathrm{tot}}=1 / 3 \int I d t\right)$. The volume expansion $\xi$ can be determined by

$$
\xi=\left(1-\frac{\mathrm{Al}_{\mathrm{aq}}^{3+}}{1 / 3 \int I d t}\right) \times \frac{\rho_{\mathrm{Al}}}{F_{W} \times \rho_{\mathrm{AlO}_{\mathrm{x}}}},
$$

where $F_{W}$ is the weight fraction of $\mathrm{Al}^{3+}$ ions in $\mathrm{AlO}_{\mathrm{x}}{ }^{25}$ Based on Eq. (6), the volume expansion for a specific anodization condition can be calculated. For the self-organized pores to form, a force promoting the medium range order must exist in addition to the force promoting the short range order. It has been proposed that $\xi$ should be $\sim 0.2$ for the medium range force to be effective. ${ }^{25}$ This means a fairly large volume expansion is needed for the anodized pores to 
arrange. Even though this reported value might have a large error, the volume expansion $\xi$ can be expected to be around $0.05-0.1$.

During the anodization, the temperature around the pores increases because of the chemical reaction heat generated at the pore-electrolyte interface. This induces thermal stress because of the thermal expansion coefficient difference between $\mathrm{Al}$ and $\mathrm{AlO}_{\mathrm{x}}$. Since the heat can be dissipated fairly quickly in the electrolyte, the temperature increase is believed to be less than $20{ }^{\circ} \mathrm{C} .{ }^{30}$ For simple estimation, thermal volume expansion $\xi_{T}$ can be described as

$$
\xi_{T}=3\left(a_{\mathrm{Al}}-a_{\mathrm{Al}_{2} \mathrm{O}_{3}}\right) \times \Delta T
$$

where $a_{\mathrm{Al}}$ and $a_{\mathrm{Al}_{2} \mathrm{O}_{3}}$ are the linear thermal expansion coefficients of $\mathrm{Al}$ and $\mathrm{Al}_{2} \mathrm{O}_{3}$, respectively. $a_{\mathrm{Al}}$ is 22.4 $\times 10^{-6} \mathrm{~K}^{-131}$ and $a_{\mathrm{Al}_{2} \mathrm{O}_{3}}$ is $7.2 \times 10^{-6} \mathrm{~K}^{-1} \cdot{ }^{32} \xi_{T}$ is about $8.52 \times 10^{-4} \mathrm{~K}^{-1}$ when the temperature increase is $20^{\circ} \mathrm{C}$. This value is much smaller than the volume expansion $\xi$ from $\mathrm{Al}$ to $\mathrm{Al}_{2} \mathrm{O}_{3}$. Therefore, the thermal stress effect from the temperature increase can be ignored.

In addition to the oxidization during the anodization, the amorphorization of $\mathrm{Al}$ crystalline phase and the implantation of the $\mathrm{Ga}^{+}$ions during the FIB patterning cause additional mechanical stress even before the anodization. ${ }^{33}$ The effective range for this stress is around $24 \mathrm{~nm}$ from the ion beam bombardment center. ${ }^{34}$ However, the exact magnitude is FIB patterning condition related (ion dose, accelerating voltage, etc.) and difficult to quantify because of the short range in the $\mathrm{Al}$ matrix.

In combination, the mechanical stress $\sigma_{\mathrm{M}}$ around the FIB patterned concaves can be expressed as:

$$
\sigma_{\mathrm{M}}=\sigma_{\xi}+\sigma_{T}+\sigma_{\mathrm{A}}+\sigma_{\mathrm{Ga}},
$$

where $\sigma_{\xi}$ is volume expansion stress, $\sigma_{\mathrm{T}}$ is temperature induced stress, $\sigma_{\mathrm{A}}$ is $\mathrm{Al}$ amorphorization stress, and $\sigma_{\mathrm{Ga}}$ is $\mathrm{Ga}^{+}$ ion implantation induced stress. Even though the magnitudes of $\sigma_{\mathrm{A}}$ and $\sigma_{\mathrm{Ga}}$ are unclear, $\sigma$ substantially contributes to the preferential oxidation and dissolution of $\mathrm{Al}$ around the FIB patterned concaves into the electrolyte.

In addition to the mechanical stress field around each FIB patterned concave, the anodization is also affected by the ion diffusion across the $\mathrm{Al} / \mathrm{AlO}_{\mathrm{x}}$ interface. The amorphorization of the $\mathrm{Al}$ crystalline phase and the implantation of the $\mathrm{Ga}^{+}$ions during the FIB patterning facilitate the ion diffusion because of the creation of easy diffusion paths. An $\mathrm{Al}-\mathrm{Ga}$ alloy is also believed to react with water and generate $\mathrm{Al}_{2} \mathrm{O}_{3} .{ }^{35}$ The more active $\mathrm{Al}$ matrix contributes to the more dominating guiding function from the FIB patterned concaves, which can effectively guide the pore growth and pattern development during the anodization.

As a combined result of the electrical field, the electrical field-induced mechanical stress field, and the more active FIB patterned Al surface, the FIB patterned concaves can effectively guide the hexagonal pore pattern growth during the anodization as shown in Fig. 1(a). More importantly, the FIB patterned concaves can guide the square pore pattern growth [Fig. 1(b)].
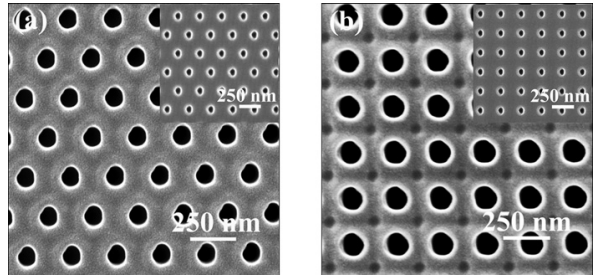

FIG. 1. Hexagonal and square pore patterns created with FIB patterning guided anodization. Both samples are anodized in $0.3 \mathrm{M}$ phosphoric acid at $20 \mathrm{~mA} / \mathrm{cm}^{2}$ current density for $6 \mathrm{~min}$. The anodization temperature is $0{ }^{\circ} \mathrm{C}$. The insets show the images after FIB patterning.

\section{FIB PATTERNED PORE CHARACTERISTICS}

To describe the FIB guided pore pattern evolution process, two terms need to be defined first. The first term is the effective pore boundary, the dash line circle in Fig. 3, which represents the oxide barrier outer layer from each pore. The second is the terminal pore size, the radius of the dash circle in Fig. 3, which represents the pore diameter when a pore stops growing without any constraining effect from its surroundings.

The electrical field and the mechanical stress field affect the neighboring pore development by influencing the oxide barrier layer growth at various interpore distances. When the interpore distance is small, the effective pore boundaries from neighboring pores overlap before the pore size reaches the terminal pore size. No effective pore boundary is seen since the entire surface is $\mathrm{AlO}_{\mathrm{x}}$ and the pore size is pseudoterminal pore size because the pores are constrained form growing larger. The FIB patterned pore arrangement remains intact and no new pore formation occurs. When the interpore distance is larger than that of the pseudoterminal pore size condition but less than that allowing for the classical formation of new pores on the $\mathrm{Al}$ surface [Fig. 2(a)], the effective pore boundaries from adjacent pores may just overlap or are only slightly apart. Stripes in hexagonal and square patterns form depending on the pore pattern involved. The slightly separated effective pore boundaries may even allow
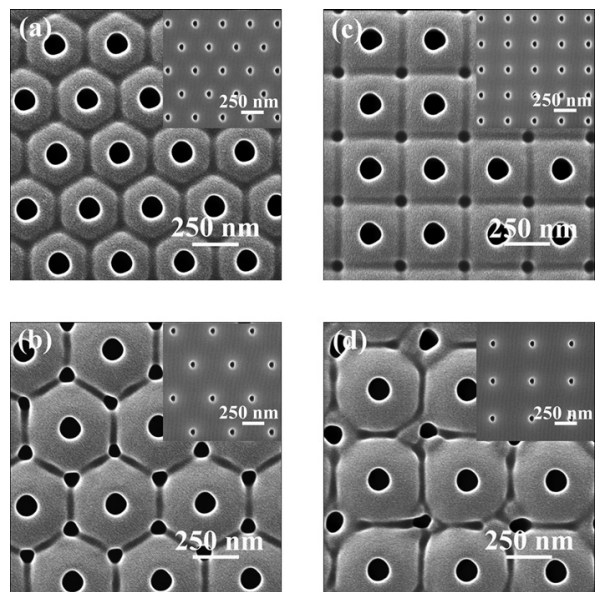

FIG. 2. FIB patterned hexagonal [(a) and (b)] and square [(c) and (d)] pore patterns after the anodization at $20 \mathrm{~mA} / \mathrm{cm}^{2}$ for $6 \mathrm{~min}$ in $0.3 \mathrm{M}$ phosphoric acid. The anodization temperature is $0^{\circ} \mathrm{C}$. The interpore distances are 350 $\mathrm{nm}[(\mathrm{a})$ and (c)] and $500 \mathrm{~nm}[(\mathrm{~b})$ and (d)], respectively. The inset shows the images after FIB patterning. 


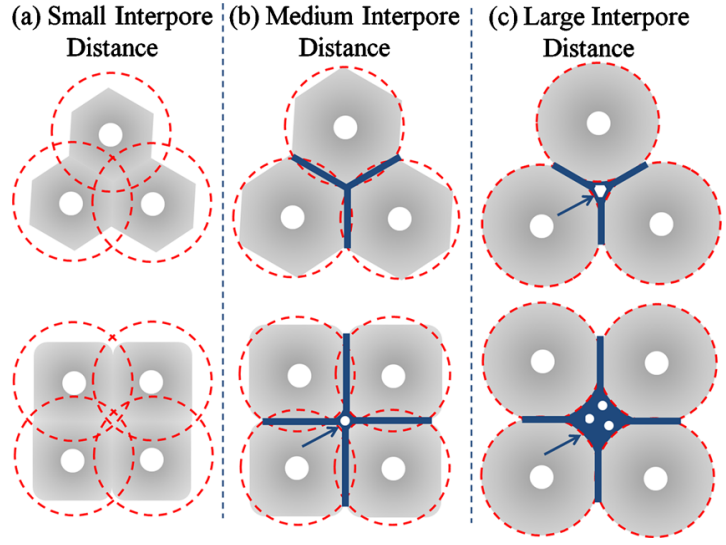

FIG. 3. (Color online) Interpore distance effect on the interaction of neighboring oxide barrier layers and new pore formation. The arrow indicates the bare Al surface areas that new pores may form. For the same terminal pore size and interpore distance, the square patterns have larger $\mathrm{Al}$ surface areas at the quadral junctions. As a result, new pores form and develop first.

new pore formation [Figs. 2(b) and 2(c)]. When the interpore distance is much larger than that of the terminal pore case, the effective pore boundaries never overlap. Random pores form and grow in-between the FIB patterned pores [Fig. $2(\mathrm{~d})]$. For the anodization of square patterns at $20 \mathrm{~mA} / \mathrm{cm}^{2}$ current density in $0.3 \mathrm{M}$ phosphoric acid at $0{ }^{\circ} \mathrm{C}$, the interpore distance should be $<150 \mathrm{~nm}$ to avoid effective pore boundary appearance and $<350 \mathrm{~nm}$ to avoid random pore formation. The terminal pore size is about $450 \mathrm{~nm}$. For hexagonal pore patterns, the interpore distance should be $<250 \mathrm{~nm}$ to avoid effective pore boundary appearance and $<500 \mathrm{~nm}$ to avoid random pore formation. The terminal pore size is almost the same as that of the square patterns.

Based on such an understanding, the effect of the interpore distance of the FIB patterned concaves during the anodization can be illustrated in Fig. 3. When the interpore distance is small, the oxide barrier layers grow and join each other before new pore nucleation/formation [Fig. 3(a)]. Only the FIB patterned pores can grow, mostly only in the depth direction. The effective pore boundaries are invisible. As the interpore distance increases, the oxide barrier layers around individual pores come in contact when the pore size is close to the terminal pore size [Fig. 3(b)]. The effective pore boundaries appear. Stripes form around the pores. The shape of the stripes reflects the shape of the barrier constricted by the neighboring pores. New pores might even form, depending on the pore arrangement. ${ }^{36}$ When the interpore distance is so large that some $\mathrm{Al}$ areas experience a negligible effect from the FIB patterned pore guidance, new pores form in the $\mathrm{Al}$ areas surrounded by the anodized oxide barrier layers [Fig. 3(c)]. This new pore formation is a direct result of the local electrical field enhancement on the bare $\mathrm{Al}$ surface based on the classical field-enhanced oxide dissolution theory. ${ }^{24-28}$ If the anodization condition is carefully controlled to an exact extent, multiple new pores may self-organize. ${ }^{11}$ Otherwise, pores arrange randomly. The arrangement of the new and FIB patterned pores depends on the original FIB patterned pore arrangement.

To further understand the FIB patterned pore growth process, the cross section images of the anodized pores are
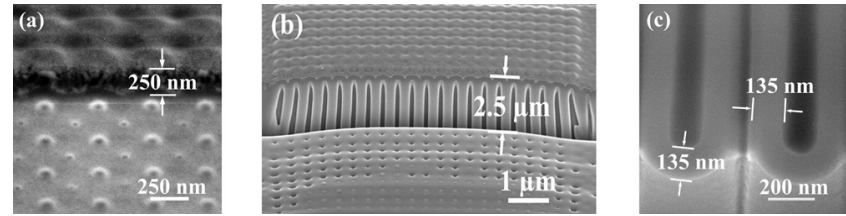

FIG. 4. Cross section images of the anodized pores for a square pattern with $350 \mathrm{~nm}$ interpore distance. The anodization condition is $20 \mathrm{~mA} / \mathrm{cm}^{2}$ for 6 min in $0.3 M$ phosphoric acid. The anodization temperature is $0{ }^{\circ} \mathrm{C}$. (a) Sample cross-sectioned $250 \mathrm{~nm}$ deep, (b) sample cross-sectioned $2.5 \mu \mathrm{m}$ deep, and (c) oxide barrier layer along the pore walls and at the pore bottoms. The viewing angle is tilted at $52^{\circ}$ so the cross-section depth appears shorter.

shown in Fig. 4 for a square pattern with a $350 \mathrm{~nm}$ interpore distance. Figure $4(\mathrm{a})$ is from the pattern cross-sectioned about $250 \mathrm{~nm}$ deep while Fig. 4(b) is from the pattern crosssectioned nearly $2.5 \mu \mathrm{m}$ deep. It can be seen that the square pore pattern arrangement is well maintained. In Fig. 4(a), new, small pores form and mesh well with the large pores. The small pores reside in the symmetrical, quadral junction centers of the electrical field and the mechanical stress field. The small pores disappear when the sample is crosssectioned to $2.5 \mu \mathrm{m}$ deep and only the FIB patterned large pores can be seen [Fig. 4(b)]. This indicates that the FIB patterned pores develop first and grow deeper than the newly formed small pores. The exact pore depth difference is a function of the FIB patterned concave size and depth and the anodization condition. Another phenomenon is that the FIB patterned pores mostly grow in the vertical direction based on the field-enhanced oxide dissolution theory discussed before. The anodized pore size is not much larger than the FIB patterned concave size, $115 \mathrm{~nm}$ versus $60 \mathrm{~nm}$. More importantly, the pore growth direction is not vertical but tilts outward at the pattern edges. This can be understood as follows. With the FIB pattern guiding effect, the pores in the patterned area develop first and faster than those in the surrounding unpatterned areas. The different pore depth growth rates induce unbalanced volume expansion at the pattern edges, which generates outward mechanical stress from the involving pore centers. The unbalanced mechanical stress causes the pores near the edges to tilt away from the pattern. For the specific anodization condition in Fig. 4, the mechanical stress field affects not only the pores along the pattern edges but also four or five pores into the pattern. Another observation related to the mechanical stress field is that the patterned surface is higher than the surrounding unpatterned area at about $40 \mathrm{~nm}$ [Fig. 4(b)]. A similar phenomenon was reported for the nanoindentation method. ${ }^{7}$ The height difference is believed to result from the $\mathrm{Al}$ amorphorization and $\mathrm{Ga}^{+}$implantation from the FIB patterning, the corresponding mechanical stress field difference, and the surface volume expansion difference at the initial anodization stage when the anodization rate in the patterned area is much higher than that in the unpatterned area. Figure 4(c) shows the oxide barrier layer along the pore walls and at the pore bottoms. The pore diameter at the pore bottom is about $115 \mathrm{~nm}$, the same as that at the top. It confirms that uniform diameter pores can be generated using the FIB guided anodization. 

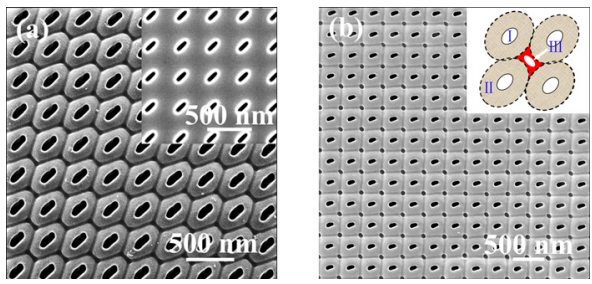

FIG. 5. (Color online) Square arrangements of elliptical pores at $350 \mathrm{~nm}$ interpore distance created by the FIB guided anodization at $20 \mathrm{~mA} / \mathrm{cm}^{2}$ current density for $6 \mathrm{~min}$ in $0.3 \mathrm{M}$ phosphoric acid. The anodization temperature is $0{ }^{\circ} \mathrm{C}$. (a) The long axis for the elliptical pores is $150 \mathrm{~nm}$ and the short axis is $50 \mathrm{~nm}$. The inset shows the FIB patterned pores before the anodization. (b) The long axis for the elliptical pores is $100 \mathrm{~nm}$ and the short axis is $50 \mathrm{~nm}$. The inset shows the formation process of the new, small pores. Areas I, II, and III represent the anodized pore, the oxide barrier layer, and the newly generated pore, respectively.

\section{UNIQUE PORE PATTERN CREATION}

So far, the discussion has been focused on the guiding function of FIB patterned concaves with carefully designed arrangements. The electrical field and the mechanical stress field are spherical around each pore. With the understanding of the effects of the electrical and mechanical stress fields, nonspherical pore shapes and unique pore arrangement can be created. Figure 5(a) inset shows elongated guiding concaves created by the FIB patterning. The interpore distance for the ellipses is $350 \mathrm{~nm}$. The concave size is $150 \mathrm{~nm}$ in the long direction and $50 \mathrm{~nm}$ in the short direction. The white rings around the FIB patterned concaves are the amorphorized and $\mathrm{Ga}^{+}$implanted $\mathrm{Al}$ regions. After the anodization in $0.3 \mathrm{M}$ phosphoric acid with $20 \mathrm{~mA} / \mathrm{cm}^{2}$ current density for 6 min at $0{ }^{\circ} \mathrm{C}$, the anodized $\mathrm{Al}$ layer around the FIB patterned concaves also shows an elliptical shape [Fig. 5(a)]; the pore size increases to $250 \mathrm{~nm}$ in the long direction and $80 \mathrm{~nm}$ in the short direction. The oxidized barrier layer thickness is about $135 \mathrm{~nm}$. During the anodization, the elliptical pores grow under the guidance of the FIB patterned concaves. The electrical and mechanical stress fields guide the pore development. The local $\mathrm{Al}$ amorphorization and the $\mathrm{Ga}^{+}$implantation activate the patterned concave surfaces and govern the initial growth of the FIB patterned pores. More importantly, the electrical field and the mechanical stress field due to the Al volume expansion exist in elliptical shapes to direct further pore growth. Since the pore centers are in a square arrangement and the interpore distance is $350 \mathrm{~nm}$ (the upper limit to avoid new pore formation), the effective pore boundaries appear but no new pores form. Figure 5(b) shows the new pore formation in-between the elongated pores after the anodization. The FIB patterned concave size is $100 \mathrm{~nm}$ in the long direction and $50 \mathrm{~nm}$ in the short direction. The FIB pattern interpore distance is $350 \mathrm{~nm}$. The anodized pore size is about $140 \mathrm{~nm}$ in the long direction and $70 \mathrm{~nm}$ in the short direction. With the continued growth of the large pores during the anodization, new pores not only form but also grow in a unique direction. The new pores in Fig. 5(b) are at the quadral junctions of the elongated pores and the pore growth direction is $90^{\circ}$ from the long direction of the original elongated concaves. The distribution of the oxide barrier layers and the formation of a new small pore are sketched in the inset of Fig. 5(b). Areas I, II, and III represent the anodized

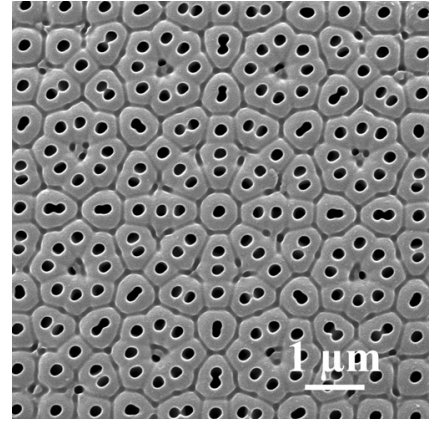

FIG. 6. Anodization result of two FIB guiding patterns overlaid at $45^{\circ}$. The anodization is carried out at $20 \mathrm{~mA} / \mathrm{cm}^{2}$ current density for $6 \mathrm{~min}$ in $0.3 \mathrm{M}$ phosphoric acid at $0{ }^{\circ} \mathrm{C}$

pore, the oxide barrier layer, and the newly generated pore, respectively. The oxide layers outside the FIB patterned pores dictate the pore shapes and the growth direction.

Comparing Figs. 5(a) and 5(b), even though the FIB patterned guiding pores have the same $350 \mathrm{~nm}$ interpore distance, the anodization result is different. This is mainly caused by the difference in the FIB patterned concave sizes. The FIB patterned pore size in Fig. 5(a) is $150 \mathrm{~nm}$ while it is only $100 \mathrm{~nm}$ in Fig. 5(b) in the long axis direction. The length of the FIB patterned pores in the short axis direction is $50 \mathrm{~nm}$ for both Figs. 5(a) and 5(b). As a result of the different concave sizes in the long direction, the geometries of the electrical field and the mechanical stress field and the growth of the oxide barrier layers around the pores are different. The electrical field defines the pseudoterminal pore size. The mechanical stress field along the oxide barrier layer growth direction and the amorphorized and $\mathrm{Ga}^{+}$implanted layer outside the pores dictate the new pore shapes and the growth direction. As a result, nonspherical pores are created by the predefined, FIB patterned elliptical pores. Because of the shorter long axis dimension, there is some space for new pore formation in Fig. 5(b). New pores grow almost perpendicular to the long axis direction and also have elongated shapes. The phenomenon in Fig. 5 again proves that the FIB patterning can guide the pore arrangement, pore shape, and new pore formation. Both spherical and nonspherical pore shapes can be created. The interpore distance and the FIB patterned concave shapes need to be jointly considered for the FIB guided pore development.

Based on the above results, more exciting pore shapes and patterns can be created by controlling the FIB patterned concave shapes and the interpore distance. This can be achieved either by limiting the interpore distance to a small value so that no new pores can be generated, or by controlling the location and shape of the FIB patterned concaves so that new pores form and grow under the guidance of the FIB patterning. This offers a versatile approach of creating different pore shapes and unique pore patterns. An interesting pattern generated is shown in Fig. 6 by the FIB patterning of two overlaid square concave patterns at $45^{\circ}$ followed by the anodization in $0.3 \mathrm{M}$ phosphoric acid at $20 \mathrm{~mA}$ current density for $6 \mathrm{~min}$ at $0{ }^{\circ} \mathrm{C}$. As seen, the FIB patterned pores grow based on the designed pattern during the anodization. The original FIB patterned pores grow and mesh with the new 
pores when the interpore distance is large enough for new pores to form. When the unpatterned Al surface area among the oxide barrier layers is large, new pores form randomly.

\section{CONCLUSIONS}

This study is focused on understanding of the FIB patterning guided anodization and pore development. Two important fields determine the existing pore growth and new pore formation: electrical field and mechanical stress field. The electrical field defines terminal pore size and pore growth rate. New pores form when the interpore distance of the guiding patterns is larger than that required for the pseudoterminal pore size. Mechanical stress field affects the pore arrangement and the oxide layer growth direction. Nonhexagonal pore arrangement, nonspherical pores, and controlled meshing of the FIB patterned pores and newly anodization pores are achieved.

\section{ACKNOWLEDGMENTS}

The authors acknowledge the financial support from National Science Foundation under Grant No. CMMI-0824741 and the Institute of Critical Technology and Applied Science of Virginia Tech.

\section{APPENDIX: DERIVATION OF EFFECTIVE DIELECTRIC PERMITTIVITY}

A column capacitor model can be used to calculate the effective dielectric permittivity $\varepsilon$. $\varepsilon_{1}$ and $\varepsilon_{2}$ represent the dielectric permittivity of $\mathrm{Al}_{2} \mathrm{O}_{3}$ and $\mathrm{Al}$, respectively. $R_{1}$ is the pore diameter and $R_{2}$ is the distance from the pore center to the oxide barrier layer outer boundary. Assuming the composition of the inner oxide layer side $\left(R_{1}\right)$ is pure $\mathrm{Al}_{2} \mathrm{O}_{3}$ and that of the outer oxide layer side $\left(R_{2}\right)$ is pure $\mathrm{Al}$; the composition between $R_{1}$ and $R_{2}$ is $\mathrm{AlO}_{\mathrm{x}}(0<\mathrm{x}<1.5)$, changing linearly from $\mathrm{Al}_{2} \mathrm{O}_{3}$ to $\mathrm{Al}$ with $R ; \varepsilon(R)$ changes linearly from the inner ring $R_{1}$ to the outer ring $R_{2}$
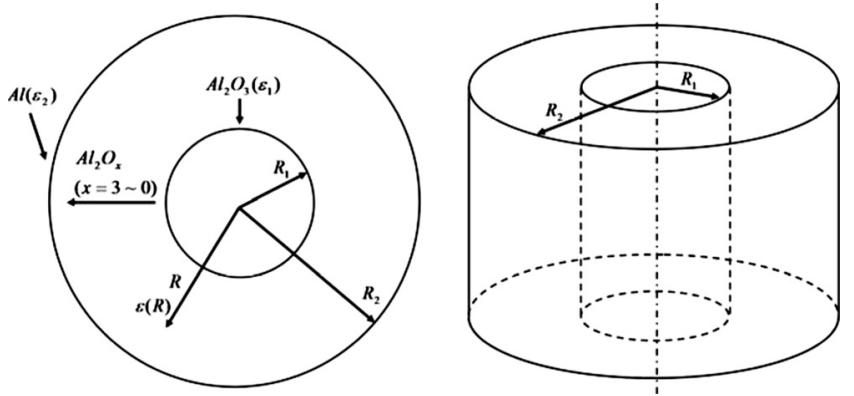

$$
\begin{aligned}
& \frac{\varepsilon(R)-\varepsilon_{1}}{\varepsilon_{2}-\varepsilon_{1}}=\frac{R-R_{1}}{R_{2}-R_{1}}, \\
& \varepsilon(R)=\frac{\left(R-R_{1}\right)\left(\varepsilon_{2}-\varepsilon_{1}\right)}{\left(R_{2}-R_{1}\right)}+\varepsilon_{1} \\
& =\frac{R\left(\varepsilon_{2}-\varepsilon_{1}\right)}{R_{2}-R_{1}}-\frac{R_{1} \varepsilon_{2}-R_{2} \varepsilon_{1}}{R_{2}-R_{1}}
\end{aligned}
$$

$$
=\frac{R\left(\varepsilon_{2}-\varepsilon_{1}\right)}{R_{2}-R_{1}}+C \quad\left(C=-\frac{R_{1} \varepsilon_{2}-R_{2} \varepsilon_{1}}{R_{2}-R_{1}}\right) .
$$

Assuming an electrical charge accumulates from the pore center axis to the wall of the inner ring, with a uniform line electron density $\lambda$ along the axis, following the Gauss theory, the voltage between the $R_{1}$ ring and the $R_{2}$ ring is

$$
\begin{aligned}
\mathrm{U}= & \int_{R_{1}}^{R_{2}} \frac{\lambda}{2 \pi \varepsilon(R)} \times \frac{1}{R} d R \\
& =\frac{\lambda}{2 \pi} \int_{R_{1}}^{R_{2}} \frac{1}{\frac{R\left(\varepsilon_{2}-\varepsilon_{1}\right)+C\left(R_{2}-R_{1}\right)}{R_{2}-R_{1}}} \times \frac{1}{R} d R \\
& =\frac{\lambda\left(R_{2}-R_{1}\right)}{2 \pi\left(\varepsilon_{2}-\varepsilon_{1}\right)} \int_{R_{1}}^{R_{2}} \frac{1}{R+C^{\prime}} \times \frac{1}{R} d R \\
& {\left[C^{\prime}=\frac{C\left(R_{2}-R_{1}\right)}{\varepsilon_{2}-\varepsilon_{1}}\right] . }
\end{aligned}
$$

For the $\int_{R_{1}}^{R_{2}}\left(1 / R+C^{\prime}\right) \times(1 / R) d R$ part

$$
\begin{aligned}
\int_{R_{1}}^{R_{2}} \frac{1}{R+C^{\prime}} \times \frac{1}{R} d R & =-\left.\frac{1}{C^{\prime}} \ln \frac{R+C^{\prime}}{R}\right|_{R_{1}} ^{R_{2}}, \\
& =-\frac{1}{C^{\prime}}\left(\ln \frac{R_{2}+C^{\prime}}{R_{2}}-\ln \frac{R_{1}+C^{\prime}}{R_{1}}\right), \\
& =-\frac{\varepsilon_{2}-\varepsilon_{1}}{R_{2} \varepsilon_{1}-R_{1} \varepsilon_{2}} \ln \frac{R_{1} \varepsilon_{2}}{R_{2} \varepsilon_{1}} .
\end{aligned}
$$

For the total equation

$$
\begin{aligned}
U & =\frac{\lambda\left(R_{2}-R_{1}\right)}{2 \pi\left(\varepsilon_{2}-\varepsilon_{1}\right)} \int_{R_{1}}^{R_{2}} \frac{1}{R+C^{\prime}} \times \frac{1}{R} d R, \\
& =-\frac{\lambda\left(R_{2}-R_{1}\right)}{2 \pi\left(R_{2} \varepsilon_{1}-R_{1} \varepsilon_{2}\right)} \ln \frac{R_{1} \varepsilon_{2}}{R_{2} \varepsilon_{1}} .
\end{aligned}
$$

Let $\varepsilon_{1}=\varepsilon_{2}=\varepsilon$, which means a homogeneous dielectric material

$$
U=\frac{\lambda}{2 \pi \varepsilon} \ln \frac{R_{2}}{R_{1}} .
$$

So the effective dielectric permittivity can be obtained as follows:

$$
\begin{aligned}
& \frac{\lambda}{2 \pi \varepsilon} \ln \frac{R_{2}}{R_{1}}=-\frac{\lambda\left(R_{2}-R_{1}\right)}{2 \pi\left(R_{2} \varepsilon_{1}-R_{1} \varepsilon_{2}\right)} \ln \frac{R_{1} \varepsilon_{2}}{R_{2} \varepsilon_{1}}, \\
& \varepsilon=\frac{\left(R_{2} \varepsilon_{1}-R_{1} \varepsilon_{2}\right) \ln \frac{R_{2}}{R_{1}}}{\left(R_{2}-R_{1}\right) \ln \frac{R_{2} \varepsilon_{1}}{R_{1} \varepsilon_{2}}} .
\end{aligned}
$$

${ }^{1}$ M. A. Kashi, A. Ramazani, M. Rahmandoust, and M. Noormohammadi, J. Phys. D 40, 4625 (2007).

${ }^{2}$ S. Ono, M. Saito, M. Ishiguro, and H. Asoh, J. Electrochem. Soc. 151, 
B473 (2004).

${ }^{3}$ M. T. Wu, I. C. Leu, and M. H. Hon, J. Vac. Sci. Technol. B 22, 2326 (2004).

${ }^{4}$ Z. X. Su, G. Hahner, and W. Z. Zhou, J. Mater. Chem. 18, 5787 (2008).

${ }^{5}$ V. V. Yuzhakov, H. C. Chang, and A. E. Miller, Phys. Rev. B 56, 12608 (1997).

${ }^{6}$ M. T. Wu, I. C. Leu, and M. H. Hon, J. Vac. Sci. Technol. B 20, 776 (2002).

${ }^{7}$ M. Jaafar, D. Navas, M. Hemandel-Vezez, J. L. Baldonedo, M. Vezquez, and A. Asenjo, Surf. Sci. 603, 3155 (2009).

${ }^{8}$ H. Asoh, K. Nishio, M. Nakao, T. Tamamura, and H. Masuda, J. Electrochem. Soc. 148, B152 (2001).

${ }^{9}$ H. Asoh, K. Nishio, M. Nakao, A. Yokoo, T. Tamamura, and H. Masuda, J. Vac. Sci. Technol. B 19, 569 (2001).

${ }^{10}$ J. Choi, S. Guido, N. Kornelius, B. W. Ralf, and U. Gosele, Chem. Mater. 15, 776 (2003).

${ }^{11}$ H. Masuda, M. Yotsuya, M. Asano, and K. Nishio, Appl. Phys. Lett. 78, 826 (2001).

${ }^{12}$ J. Choi, R. B. Wehrspohn, and U. Gosele, Electrochim. Acta 50, 2591 (2005).

${ }^{13}$ Z. J. Sun and H. K. Kim, Appl. Phys. Lett. 81, 3458 (2002).

${ }^{14}$ N. W. Liu, A. Datta, C. Y. Liu, and Y. L. Wang, Appl. Phys. Lett. 82, 1281 (2003).

${ }^{15}$ C. Y. Peng, C. Y. Liu, N. W. Liu, H. H. Wang, A. Datta, and Y. L. Wang, J. Vac. Sci. Technol. B 23, 559 (2005).

${ }^{16}$ C. Y. Liu, A. Datta, and Y. L. Wang, Appl. Phys. Lett. 78, 120 (2001).

${ }^{17}$ K. Lu, J. Nanosci. Nanotechnol. 9, 2598 (2009).

${ }^{18}$ K. Lu and J. Z. Zhao, J. Nanosci. Nanotechnol. 10, 6760 (2010).
${ }^{19}$ J. Zhao, K. Lu, B. Chen, and Z. Tian, Ceram. Trans. 223, 47 (2010).

${ }^{20}$ H. Asoh, S. Ono, T. Hirose, I. Takatori, and H. Masuda, Jpn. J. Appl. Phys., Part 1 43, 6342 (2004).

${ }^{21}$ H. Asoh, S. Ono, T. Hirose, M. Nakao, and H. Masuda, Electrochim. Acta 48, 3171 (2003).

${ }^{22}$ O. Jessensky, F. Muller, and U. Gosele, Appl. Phys. Lett. 72, 1173 (1998).

${ }^{23}$ G. E. Thompson and G. C. Wood, Nature (London) 290, 230 (1981).

${ }^{24}$ J. Choi, Y. Luo, R. B. Wehrspohn, R. Hillebrand, J. Schilling, and U. Gosele, J. Appl. Phys. 94, 4757 (2003).

${ }^{25}$ T. P. Hoar and N. F. Mott, J. Phys. Chem. Solids 9, 97 (1959).

${ }^{26}$ J. P. O'Sulliva and G. C. Wood, Proc. R. Soc. London 317, 511 (1970).

${ }^{27}$ V. P. Parkhutik and V. I. Shershulsky, J. Phys. D 25, 1258 (1992).

${ }^{28}$ S. K. Thamida and H. C. Chang, Chaos 12, 240 (2002).

${ }^{29}$ A. I. Vorobyova, E. A. Outkina, and A. A. Khodin, Russ. Microelectron. 36, 384 (2007).

${ }^{30}$ R. M. Saleh and A. A. El Hosary, J. Therm. Anal. 26, 263 (1983).

${ }^{31}$ D. R. Lide, CRC Handbook of Chemistry and Physics (CRC, Boston, 1992), pp. 12-119.

${ }^{32}$ S. J. Schneider, Ceramics and Glasses, Engineered Materials Handbook Vol. 4 (ASM International, Cleveland, OH, 1991), p. 30.

${ }^{33}$ H. Takahashi, K. Fujimoto, H. Konno, and M. Magayama, J. Electrochem. Soc. 131, 1856 (1984).

${ }^{34}$ L. A. Giannuzzi and F. A. Stevie, Introduction to Focused Ion Beams: Instrumentation, Theory, Techniques and Practice (Springer, New York, 2005).

${ }^{35}$ J. M. Woodall, Making of hydrogen from aluminum, 2007. http:// hydrogen.ecn.purdue.edu/

${ }^{36}$ Z. Tian, K. Lu, and B. Chen, Nanotechnology 21, 405301 (2010). 